\title{
REVIEW
}

Open Access

\section{Management of intrathoracic and cervical anastomotic leakage after esophagectomy for esophageal cancer: a systematic review}

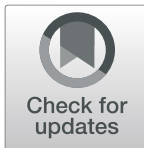

Moniek H. P. Verstegen ${ }^{1 *}$ (D), Stefan A. W. Bouwense ${ }^{1}$, Frans van Workum', Richard ten Broek', Peter D. Siersema ${ }^{2}$, Maroeska Rovers ${ }^{3}$ and Camiel Rosman ${ }^{1}$

\begin{abstract}
Background: Anastomotic leakage (0-30\%) after esophagectomy is a severe complication and is associated with considerable morbidity and mortality. The aim of this study was to determine which treatment for anastomotic leakage after esophagectomy have the best clinical outcome, based on the currently available literature.

Methods: A systematic literature search was performed in Medline, Embase, and Web of Science until April 2017. All studies reporting on the specific treatment of cervical or intrathoracic anastomotic leakage following esophagectomy with gastric tube reconstruction for esophageal or cardia cancer were included. The primary outcome parameter was postoperative mortality. Methodological quality was assessed by the Newcastle-Ottawa Quality Assessment Scale.
\end{abstract}

Results: Nineteen retrospective cohort studies including 273 patients were identified. Methodological quality of all studies was poor to moderate. Mortality rates of intrathoracic anastomotic leakages in the treatment groups were as follows: conservative (14\%), endoscopic stent (8\%), endoscopic drainage (8\%), endoscopic vacuum-assisted closure system (0\%), and surgery treatment group (50\%). Mortality rates of cervical anastomotic leakages in the treatment groups were as follows: conservative (8\%), endoscopic stent (29\%), and endoscopic dilatation (0\%).

Discussion: Due to small cohorts, heterogeneity between studies, and lack of data regarding leakage characteristics, no evidence supporting a specific treatment for anastomotic leakage after esophagectomy was found. A severity score based on leakage characteristics instead of treatment given is essential for determining the optimal treatment of anastomotic leakage. In the absence of robust evidence-based treatment guidelines, we suggest customized treatment depending on sequelae of the leak and clinical condition of the patient. PrDepartment of Surgery, Radboudumc, P.O.B. 9101/618 NLactical advices are provided.

Trial registration: Registration number PROSPERO: CRD42016032374.

Keywords: Anastomotic, Leakage, Intrathoracic, Cervical, Esophagectomy, Treatment

\footnotetext{
* Correspondence: moniek.verstegen@radboudumc.nl;

Moniek.Verstegen@radboudumc.nl

'Department of Surgery, Radboudumc, Geert Grooteplein Zuid 10, 6525 GA

Nijmegen, The Netherlands

Full list of author information is available at the end of the article
}

(c) The Author(s). 2019 Open Access This article is distributed under the terms of the Creative Commons Attribution 4.0 International License (http://creativecommons.org/licenses/by/4.0/), which permits unrestricted use, distribution, and reproduction in any medium, provided you give appropriate credit to the original author(s) and the source, provide a link to the Creative Commons license, and indicate if changes were made. The Creative Commons Public Domain Dedication waiver (http://creativecommons.org/publicdomain/zero/1.0/) applies to the data made available in this article, unless otherwise stated. 


\section{Background}

The incidence of esophageal carcinoma is increasing. Yearly, 450,000 patients are diagnosed with esophageal cancer worldwide, and approximately 135,000 (30\%) of these patients will undergo curative resection $[1,2]$. Anastomotic leakage $(0-30 \%)$ is a severe complication after esophagectomy $[3,4]$. The occurrence of anastomotic leakage is associated with a prolonged length of stay on the intensive care unit (ICU) and within the hospital, a reduced quality of life, high costs, and an increased mortality rate [4-7].

The severity of anastomotic leakage ranges from asymptomatic to full-blown sepsis with multiple organ failure. Factors that may influence the severity of the anastomotic leakage are the location of the anastomosis (intrathoracic or cervical), the size and circumference of the defect, and the extent of contamination [8]. Factors that influence the severity of anastomotic leakage might also impact the most appropriate treatment strategy. Treatment of anastomotic leakage ranges from "conservative" (nil by mouth, antibiotics, gastric drainage, enteral or parenteral feeding, and drainage through percutaneous tubes) to endoscopic treatment with stents or endoscopic vacuum-assisted closure (VAC) devices, and surgery [9]. However, no generally accepted treatment strategy for the treatment of anastomotic leakage after esophagectomy currently exists [10].

The aim of this study was to determine which treatment for a cervical or intrathoracic anastomotic leakage after esophagectomy with gastric tube reconstruction has the best clinical outcome, based on literature findings.

\section{Methods}

This review was registered in the PROSPERO database for systematic reviews under number CRD42016032374 [11]. It was performed according to the Preferred Reporting Items for Systematic Reviews and Meta-analyses (PRISMA) guidelines, and the PRISMA checklist is shown online in Additional file 1: Appendix 1 [12]. A systematic literature search was performed in Medline, Embase, Web of Science, and the Cochrane Library for studies published from inception to April 24, 2017. The search terms used were esophageal neoplasm or esophagectomy, and anastomotic leak or gastrointestinal leak, and synonyms, and were restricted to title, abstract, and keywords (see Additional file 1: Appendix 2 for the full electronic search strategy). There were no restrictions regarding language, year of publication, or publication status.

\section{Study selection and data extraction}

Titles, abstracts, and subsequently full-text articles were screened independently by two authors (M.V. and S.B.), and eligibility was assessed. All studies concerning the treatment of cervical and/or intrathoracic anastomotic leakage after esophagectomy for cancer of the esophagus or gastric cardia with gastric tube reconstruction were included. Studies not reporting the location of the anastomosis were excluded. Studies primarily investigating the treatment of other disorders affecting interruption of esophageal integrity such as iatrogenic injuries, spontaneous ruptures, conduit line dehiscence, or necrosis of the gastric conduit were excluded. In addition, review articles, editorials, case reports or cohort studies including fewer than five patients per specific treatment strategy, animal studies, and studies in children were excluded. Disagreement on eligibility was resolved after discussion. Reference lists of all included articles were screened manually to identify initially missed, but relevant studies. Data was extracted by M.V. and S.B. independently and entered into an electronic database (IBM SPSS for Windows version 22.0, Armonk, NY).

\section{Assessment of methodological quality}

The risk of bias was assessed using the Newcastle-Ottawa Quality Assessment Scale for cohort studies [13]. This scale rates studies on 3 sources of bias (selection, comparability, and outcome) based on 8 criteria. Each criterion is awarded with 1 star except comparability, which is awarded a maximum of 2 stars. For this systematic review, studies scoring 7-9 stars were considered to be of high methodological quality, studies scoring 4-6 stars were considered to be of moderate methodological quality, and studies scoring 1-3 stars were considered to be of poor methodological quality. The methodological quality of all included studies was assessed independently by 2 authors (M.V. and S.B.). Disagreements were resolved by discussion and consensus with a third reviewer (C.R.).

\section{Study characteristics, leakage characteristics, and outcome parameters}

The following study characteristics were extracted: first author, year of publication, country of origin, number of included patients, study design (prospective or retrospective), type of modality used to diagnose the leakage, type of operation, and location of the anastomosis.

Data regarding leak characterization included the following: time from surgery to diagnosis of the leakage, time from diagnosis to treatment of the leakage, the mean interval of the leakage treatment, circumference of the leakage $(0-25 \%, 25-50 \%, 50-75 \%$, and $75-100 \%)$, length of the leakage (in centimeters), gastric conduit overall condition (vital, ischemic, or necrotic), and extent of the contamination (i.e., none, mediastinal fluid collections, or pleural fluid collections).

The primary outcome parameter was mortality rate. The secondary outcome parameters were as follows: 
success rate (when not defined by the author, defined as alive and no persisting leakage during time of follow-up), severe complications occurring after anastomotic leakage treatment (Clavien-Dindo [14] $\geq 3$ ), reintervention rate (all surgical, endoscopic, and radiological reinterventions), reoperation rate, new onset of (multiple) organ failure, hospital length of stay, ICU length of stay, and quality of life.

\section{Analysis}

Due to heterogeneity between studies, no meta-analysis could be performed. The weighted percentages and means were calculated to summarize the treatment outcomes for each subgroup.

\section{Results}

\section{Included studies}

Nineteen studies, including a total of 273 patients, met the inclusion criteria of this systematic review. A summary of the screening and selection process is shown in Fig. 1.

\section{Study characteristics}

All 19 included studies were retrospective cohort studies [15-33], of which 2 studies were comparative cohort studies (Table 1) $[15,16]$. An intrathoracic anastomosis was performed in 200 patients and a cervical anastomosis in 73 patients. The incidence of anastomotic leakage could be calculated in only 2 studies; the incidence rates were $1 \%$ and $17 \%$, respectively $[16,20]$. The average age of the patients was described in 6 studies; the weighted mean was 58.0 years (range $28-92$ years) $[16,20,21,28,31,33]$. Neo-adjuvant treatment was reported in 1 study, in which none was given [24]. Tumor characteristics were reported in 2 studies; in 1 study, stage I esophageal cancer was found in 3 patients, stage IIA in 9, stage IIB patients in 11 patients, and stage III in 5 patients [33]. In 1 study, 8 patients were diagnosed with adenocarcinoma and 2 patients with squamous cell carcinoma [31]. In 3 studies, operations were performed minimally invasively $[15,25,30]$.

In 17 studies, the following modalities were used to diagnose anastomotic leakage: contrast swallow examination ( $n=15$ studies), endoscopy ( $n=11$ studies), and computed tomography (CT) scan ( $n=10$ studies). In 6 studies, a conservative treatment was performed consisting of the administration of antibiotics, nil by mouth, enteral tube feeding, gastric drainage and (percutaneous) drainage of the mediastinum, thoracic cavity, and/or wound [18, 20, 22, 24, 29, 32]. Patients were treated by endoscopic vacuum-assisted wound closure (VAC) system in 1 study [17], by endoscopic drainage in 4 studies [20, 22, 30, 33], and by endoscopic stent placement in 7 studies $[15,21,23,25-$ $27,31]$. In 2 studies ( $n=13$ patients), endoscopic balloon dilatation was performed to improve the healing of the leak $[16,18]$. One study performed a re-thoracotomy with revision of the anastomosis (Table 2) [19]. Quality of life was not reported in any of the studies. Severe complications were described in

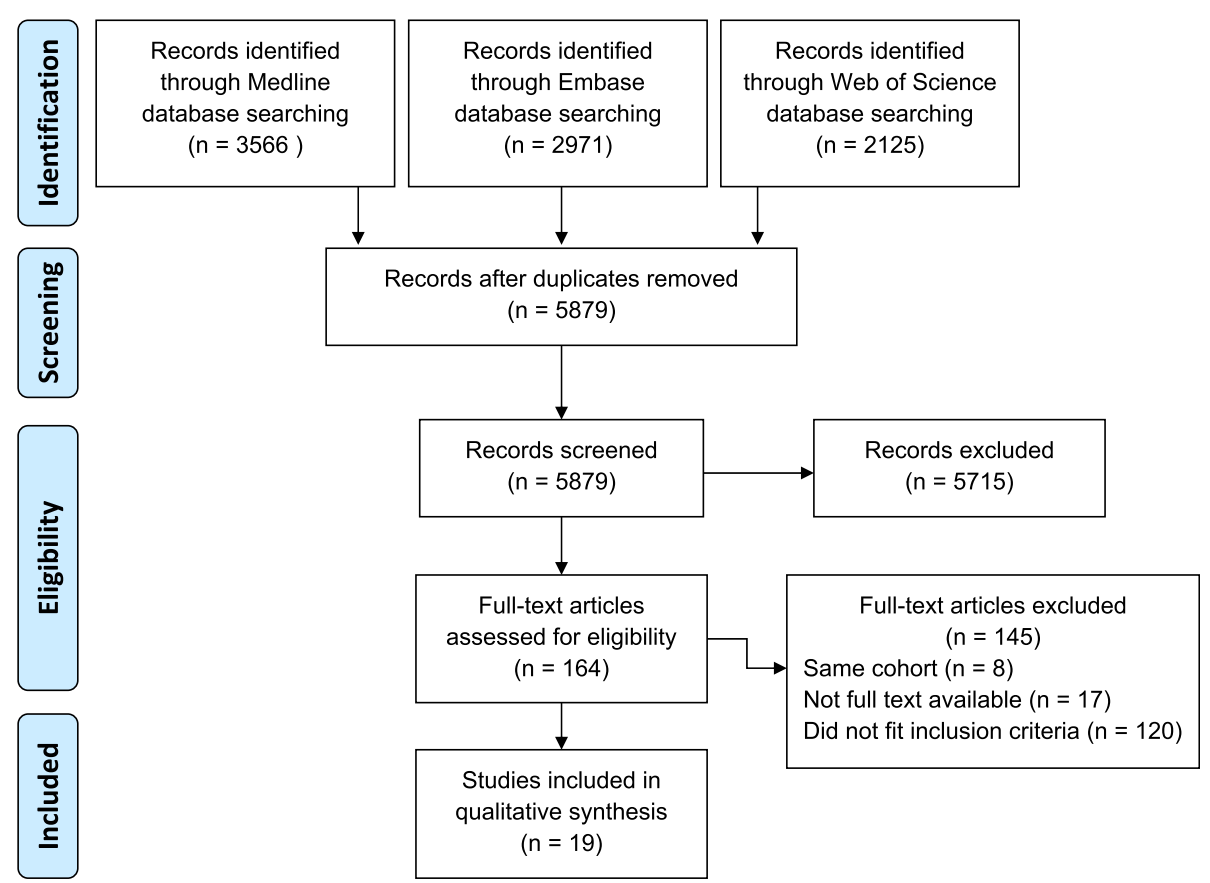

Fig. 1 Summary of screening and selection process, PRISMA diagram 
Table 1 General study characteristics

\begin{tabular}{|c|c|c|c|c|c|}
\hline Author & Country & Design & $\begin{array}{l}\text { Patients } \\
(n)\end{array}$ & Type of operation & Outcomes reported \\
\hline \multicolumn{6}{|l|}{ Intrathoracic } \\
\hline Griffin 2001 [18] & UK & NC & 13 & NA & Mortality/success/complication/reoperation \\
\hline $\begin{array}{l}\text { Holscher } 2003 \\
{[19]}\end{array}$ & $\mathrm{DE}$ & NC & 6 & Ivor Lewis & Mortality/success/complication/reoperation \\
\hline $\begin{array}{l}\text { Hunerbein } 2004 \\
{[21]}\end{array}$ & $\mathrm{DE}$ & NC & 9 & $\begin{array}{l}\text { Transhiatal or Ivor } \\
\text { Lewis }\end{array}$ & $\begin{array}{l}\text { Mortality/success/complication/reintervention/reoperation/hospital and } \\
\text { ICU stay }\end{array}$ \\
\hline Kauer 2008 [23] & $\mathrm{DE}$ & NC & 10 & Ivor Lewis & Mortality/success/complication/reintervention/reoperation \\
\hline $\begin{array}{l}\text { Tuebergen } 2008 \\
\text { [31] }\end{array}$ & $\mathrm{DE}$ & NC & 18 & Ivor Lewis & Mortality/success/reintervention/reoperation/hospital stay \\
\hline Qin 2010 [29] & $\mathrm{CN}$ & NC & 5 & Left thoracotomy & Mortality/success/hospital stay \\
\hline Hu 2011 [20] & $C N$ & C & 23 & Ivor Lewis & Mortality/success/reoperation/hospital stay/ICU stay \\
\hline Hu 2011 [20] & $\mathrm{CN}$ & C & 17 & Ivor Lewis & Mortality/success/reoperation/hospital stay/ICU stay \\
\hline Jiang 2011 [22] & $\mathrm{CN}$ & C & 7 & Left thoracotomy & Mortality/success/complication/hospital stay \\
\hline Jiang 2011 [22] & $\mathrm{CN}$ & C & 25 & Left thoracotomy & Mortality/success/complication/hospital stay \\
\hline Yin 2012 [33] & $\mathrm{CN}$ & NC & 28 & Ivor Lewis & Mortality/success/complication/reintervention \\
\hline Al-Issa $2014[15]$ & DK & NC & 15 & Ivor Lewis (some MIE) & Mortality/success/complication/reintervention/hospital stay \\
\hline Bludau 2014 [17] & $\mathrm{DE}$ & NC & 5 & Ivor Lewis & Mortality/success \\
\hline Shuto 2017 [30] & $J P$ & NC & 19 & Ivor Lewis (some MIE) & Mortality/success/complication/reintervention \\
\hline \multicolumn{6}{|l|}{ Cervical } \\
\hline $\begin{array}{l}\text { Orringer } 1986 \\
{[28]}\end{array}$ & US & NC & 5 & Orringer & Mortality/success/complication/reintervention \\
\hline Bhasin $2000[16]$ & IN & NC & 8 & Orringer & Mortality/success/complication/reintervention \\
\hline Korst 2005 [24] & US & NC & 13 & $\begin{array}{l}\text { Mckeown or left } \\
\text { thoracotomy }\end{array}$ & Mortality/success/complication/reintervention/hospital stay \\
\hline $\begin{array}{l}\text { Lindeman } 2008 \\
\text { [27] }\end{array}$ & AT & NC & 6 & Mckeown or Orringer & Mortality/success/complication/reintervention \\
\hline $\begin{array}{l}\text { Larburu } 2013 \\
{[25]}\end{array}$ & ES & NC & 9 & $\begin{array}{l}\text { Mckeown or Orringer } \\
\text { (both MIE) }\end{array}$ & Mortality/success/complication/reoperation \\
\hline $\begin{array}{l}\text { Leenders } 2013 \\
{[26]}\end{array}$ & $\mathrm{NL}$ & NC & 9 & Orringer & Mortality/success/complication/reintervention/reoperation/hospital stay \\
\hline $\begin{array}{l}\text { Van Rossum } \\
2017[32]\end{array}$ & $\mathrm{NL}$ & NC & 23 & Mckeown & $\begin{array}{l}\text { Mortality/success/complication/reintervention/reoperation/hospital } \\
\text { and ICU stay }\end{array}$ \\
\hline
\end{tabular}

Complication = severe complication rate, hospital stay = hospital length of stay, ICU stay = ICU length of stay, Ivor Lewis = esophagectomy by laparotomy and thoracotomy with intrathoracic anastomosis, McKeown = esophagectomy by laparotomy and thoracotomy with cervical anastomosis, MIE = minimally invasive esophagectomy, mortality $=$ mortality rate, Orringer $=$ transhiatal esophagectomy with cervical anastomosis, reintervention $=$ reintervention rate, reoperation $=$ reoperation rate, success $=$ success rate C comparative, NA not available, NC non-comparative

AT Austria, CN China, DE Germany, DK Denmark, ES Spain, IN India, JP Japan, NL Netherlands, UK United Kingdom, US United States of America

15 studies $[15,16,18,19,21-28,30,32,33]$, but none of the included studies reported the severity of complications according to the Clavien-Dindo scale.

\section{Methodological quality}

Methodological quality of the included studies is described in Table 3. The quality of the included studies was poor in 9 studies $[15,18,19,23,24,26-29]$ and moderate in 10 studies [16, 17, 20-22, 25, 30-33]. Ten of the 19 studies reported on selected cases (i.e., excluding the critically ill and intensive care patients) $[15,16$, $18,26-31,33]$, which is not representative of the general hospitalized population with an anastomotic leakage after esophageal resection.

\section{Characteristics of anastomotic leakage}

The mean time from surgery to diagnosis of the anastomotic leakage was reported in 9 studies and was 9 days (range 2-30) [16, 19-22, 27-29, 33]. Only 2 studies reported the time from diagnosing the leakage and the treatment of it (mean 8 days (range $0-20$ )) $[16,26]$. The mean duration of the leakage treatment was reported in 11 studies and was 34 days $[16,17$, $21,22,24,26-29,31,33]$. Two studies reported the percentage of the circumference of the leak; 1 study 
Table 2 Clinical study characteristics

\begin{tabular}{|c|c|c|c|c|}
\hline Author & $\begin{array}{l}\text { Patients } \\
(n)\end{array}$ & $\begin{array}{l}\text { Diagnosis of } \\
\text { leakage }\end{array}$ & General treatment & $\begin{array}{l}\text { Investigational } \\
\text { treatment }\end{array}$ \\
\hline \multicolumn{5}{|l|}{ Intrathoracic } \\
\hline Griffin 2001 [18] & 13 & Contrast/endoscopy & $\begin{array}{l}\text { Antibiotics, nil by mouth, enteral feeding tube, gastric, mediastinal, } \\
\text { and thoracic drainage }\end{array}$ & $\begin{array}{l}\text { Conservative } \\
\text { treatment }\end{array}$ \\
\hline $\begin{array}{l}\text { Holscher } 2003 \\
{[19]}\end{array}$ & 6 & $\begin{array}{l}\text { Contrast/endoscopy/ } \\
\mathrm{CT}\end{array}$ & Gastric drainage & Surgery \\
\hline $\begin{array}{l}\text { Hunerbein } 2004 \\
{[21]}\end{array}$ & 9 & $\begin{array}{l}\text { Contrast/ } \\
\text { endoscopy }\end{array}$ & Antibiotics, thoracic drainage & Stent (plastic) \\
\hline Kauer 2008 [23] & 10 & $\begin{array}{l}\text { Contrast/ } \\
\text { endoscopy }\end{array}$ & Mediastinal drainage & Stent (SEMS) \\
\hline $\begin{array}{l}\text { Tuebergen } 2008 \\
\text { [31] }\end{array}$ & 18 & $\begin{array}{l}\text { Contrast/ } \\
\text { endoscopy }\end{array}$ & $\begin{array}{l}\text { Antibiotics, nil by mouth, enteral feeding tube, gastric, mediastinal, } \\
\text { and thoracic drainage }\end{array}$ & Stent (SEMS) \\
\hline Qin 2010 [29] & 5 & Contrast & $\begin{array}{l}\text { Antibiotics, nil by mouth, enteral feeding tube, gastric, mediastinal, } \\
\text { and thoracic drainage }\end{array}$ & $\begin{array}{l}\text { Conservative } \\
\text { treatment }\end{array}$ \\
\hline Hu 2011 [20] & 23 & Contrast/CT & Antibiotics, nil by mouth, enteral feeding tube, thoracic drainage & Endoscopic drainage \\
\hline Hu 2011 [20] & 17 & Contrast/CT & $\begin{array}{l}\text { Antibiotics, nil by mouth, enteral feeding tube, gastric and thoracic } \\
\text { drainage }\end{array}$ & $\begin{array}{l}\text { Conservative } \\
\text { treatment }\end{array}$ \\
\hline Jiang 2011 [22] & 7 & Contrast & Nil by mouth, enteral feeding tube, gastric and thoracic drainage & $\begin{array}{l}\text { Conservative } \\
\text { treatment }\end{array}$ \\
\hline Jiang 2011 [22] & 25 & Contrast & Nil by mouth, enteral feeding tube, thoracic drainage & Endoscopic drainage \\
\hline Yin 2012 [33] & 28 & Contrast/CT & Nil by mouth, enteral feeding tube, gastric drainage & Endoscopic drainage \\
\hline Al-Issa 2014 [15] & 15 & Endoscopy/CT & Antibiotics, nil by mouth, enteral feeding tube, thoracic drainage & Stent (SEMS) \\
\hline Bludau 2014 [17] & 5 & $\begin{array}{l}\text { Contrast/ } \\
\text { endoscopy/CT }\end{array}$ & NA & Endoscopic VAC \\
\hline Shuto 2017 [30] & 19 & $\begin{array}{l}\text { Contrast/ } \\
\text { endoscopy/CT }\end{array}$ & $\begin{array}{l}\text { Antibiotics, nil by mouth, enteral feeding tube, gastric, mediastinal, } \\
\text { and thoracic drainage }\end{array}$ & Endoscopic drainage \\
\hline \multicolumn{5}{|l|}{ Cervical } \\
\hline $\begin{array}{l}\text { Orringer } 1986 \\
{[28]}\end{array}$ & 5 & NA & $\begin{array}{l}\text { Nil by mouth, enteral feeding tube, gastric drainage, wound } \\
\text { drainage }\end{array}$ & Endoscopic dilatation \\
\hline Bhasin 2000 [16] & 8 & Contrast & Nil by mouth, enteral feeding tube, wound drainage & Endoscopic dilatation \\
\hline Korst 2005 [24] & 13 & $\begin{array}{l}\text { Contrast/ } \\
\text { endoscopy/CT }\end{array}$ & Antibiotics, wound drainage & $\begin{array}{l}\text { Conservative } \\
\text { treatment }\end{array}$ \\
\hline $\begin{array}{l}\text { Lindeman } 2008 \\
\text { [27] }\end{array}$ & 6 & NA & Nil by mouth, wound drainage & Stent (SEMS) \\
\hline $\begin{array}{l}\text { Larburu } 2013 \\
{[25]}\end{array}$ & 9 & $\begin{array}{l}\text { Contrast/ } \\
\text { endoscopy/CT }\end{array}$ & NA & Stent (SEMS) \\
\hline $\begin{array}{l}\text { Leenders } 2013 \\
{[26]}\end{array}$ & 9 & NA & Wound drainage or percutaneous drainage & Stent (SEMS) \\
\hline $\begin{array}{l}\text { Van Rossum } \\
2017[32]\end{array}$ & 23 & $\begin{array}{l}\text { Contrast/ } \\
\text { endoscopy/CT }\end{array}$ & $\begin{array}{l}\text { Nil by mouth, enteral feeding tube, gastric drainage, wound } \\
\text { drainage }\end{array}$ & $\begin{array}{l}\text { Conservative } \\
\text { treatment }\end{array}$ \\
\hline
\end{tabular}

Conservative treatment = antibiotics/nil by mouth/enteral feeding tube/gastric drainage/mediastinal drainage/thoracic drainage/percutaneous drainage/wound drainage; contrast $=$ contrast swallow examination

CT computerized tomography, NA not available, SEMS self-expandable metallic stent

included patients with a defect less than $2 / 3$ of the circumference [31], the other study with a defect between 10 and $30 \%$ of the circumference [27]. The length of the leak in centimeters was reported in 2 studies, 1 study only included patients with a leak > $1 \mathrm{~cm}$ [15] and 1 study only included patients with a leak $>0.5 \mathrm{~cm}$ [23]. No studies reported data on the general condition of the gastric tube. Five studies reported data on contamination that was caused by the leak but used different descriptions (e.g., small vs. extended, cervical vs. intrathoracic manifestation of the cervical leakages) $[21,22,24,25,32]$. In 4 patients, the leakage was associated with fistula formation to the airways $(n=2)$ or gastric conduit necrosis $(n=2)$ [25, 31]. None of the studies reported outcomes per anastomotic leakage characteristic, and 


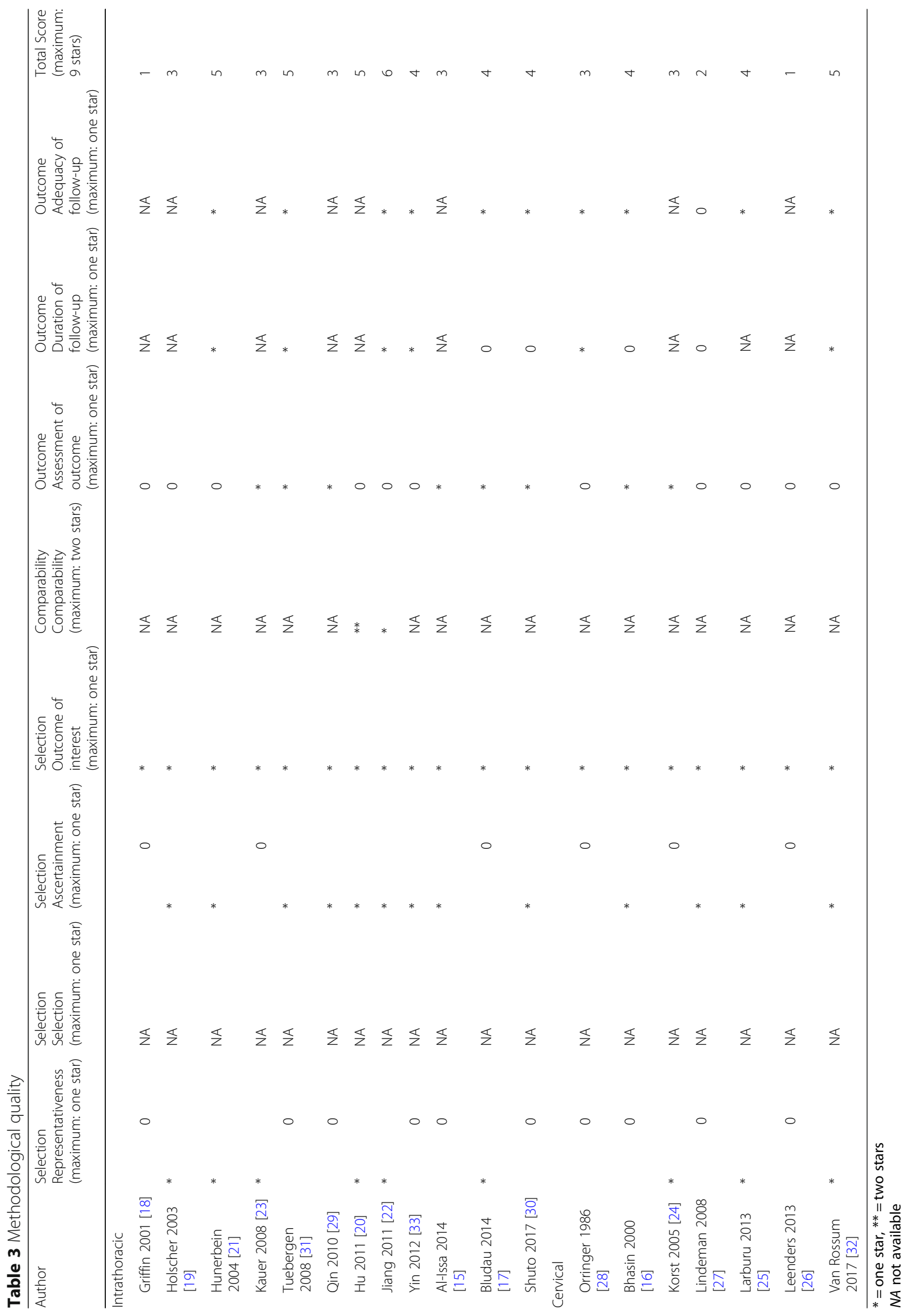


Table 4 Primary outcome: mortality rate

\begin{tabular}{|c|c|c|c|}
\hline & Studies, $n$ & Included patients, $n$ & Mortality, $n(\%)$ \\
\hline \multicolumn{4}{|l|}{ Overall } \\
\hline Conservative & 6 & 78 & $9(12 \%)$ \\
\hline \multicolumn{4}{|c|}{ Endoscopic } \\
\hline Stent & 7 & 76 & $11(14 \%)$ \\
\hline Drainage & 4 & 95 & $8(8 \%)$ \\
\hline Endoscopic VAC & 1 & 5 & $0(0 \%)$ \\
\hline Dilatation & 2 & 13 & $0(0 \%)$ \\
\hline Surgical & 1 & 6 & $3(50 \%)$ \\
\hline \multicolumn{4}{|c|}{ Intrathoracic anastomotic leakage } \\
\hline Conservative & 4 & 42 & $6(14 \%)$ \\
\hline \multicolumn{4}{|c|}{ Endoscopic } \\
\hline Stent & 4 & 52 & $4(8 \%)$ \\
\hline Drainage & 4 & 95 & $8(8 \%)$ \\
\hline Endoscopic VAC & 1 & 5 & $0(0 \%)$ \\
\hline Surgical & 1 & 6 & $3(50 \%)$ \\
\hline \multicolumn{4}{|c|}{ Cervical anastomotic leakage } \\
\hline Conservative & 2 & 36 & $3(8 \%)$ \\
\hline \multicolumn{4}{|c|}{ Endoscopic } \\
\hline Stent & 3 & 24 & $7(29 \%)$ \\
\hline Dilatation & 2 & 13 & $0(0 \%)$ \\
\hline
\end{tabular}

VAC vacuum-assisted closure

therefore, no further analysis of the effectiveness of different treatment modalities per leakage characteristic could be performed.

\section{Outcomes of anastomotic leakage treatment All studies}

The overall mortality was $11 \%$ ( $31 / 273$ patients). The mortality rates were as follows: $12 \%$ (9/78 patients) in the conservative group, $14 \%$ (11/76 patients) in the endoscopic stent group, 8\% (8/95 patients) in the endoscopic drainage group, $0 \%$ (0/5 patients) in the endoscopic VAC therapy, $0 \%(0 / 13$ patients $)$ in the endoscopic dilatation group, and 50\% (3/6 patients) in the surgical treatment group (Table 4). Only two studies reported the new onset of (multiple) organ failure, respectively $14 \%$ ( $1 / 7$ patients) and $50 \%$ (3/6 patients) of patients $[19,22]$. Other outcome parameters are reported in Table 5.

\section{Subgroup - intrathoracic anastomotic leakage}

The overall mortality after intrathoracic anastomotic leakage was $11 \%$ (21/200 patients). The mortality rates were as follows: $14 \%$ (6/42 patients) in the conservative group, $8 \%$ (4/52 patients) in the endoscopic stent group,
$8 \%$ (8/95 patients) in the endoscopic drainage group, $0 \%$ (0/5 patients) in the endoscopic VAC therapy group, and $50 \%$ (3/6 patients) in the surgical treatment group (Table 4). The reintervention rate was higher in the endoscopic stent group compared to other treatment groups: 19 patients (37\%) needed at least 1 reintervention, most often because of stent migration. Table 6 provides an overview of the other outcome measures.

\section{Subgroup-cervical anastomotic leakage}

The overall mortality after cervical anastomotic leakage was $14 \%$ (10/73 patients). The mortality rates were as follows: $8 \%$ (3/36 patients) in the conservative treatment group, $29 \%$ (7/24 patients) in the endoscopic stent group, and $0 \%(0 / 13$ patients) in the endoscopic dilatation group (Table 4). The reintervention and reoperation rates were $53 \%$ ( $8 / 15$ patients) and $44 \%$ (4/9 patients) in the endoscopic stent group. Table 7 provides an overview of the other outcome measures.

\section{Discussion}

This is the first systematic review summarizing the results of different treatment strategies for anastomotic leakage in patients after esophagectomy with gastric tube reconstruction.

Results on conservative, endoscopic, and surgical treatment were reported in 6 studies, 14 studies, and 1 study, respectively. The mean overall mortality rate was $11 \%$. In studies reporting the outcome of conservative treatment, the mean mortality was $12 \%$, in the stent placement group 14\%, and in the endoscopic drainage group $8 \%$. For endoscopic VAC, endoscopic dilatation, and surgical treatment, the mortality rate could not reliably be estimated due to a low number of patients reported.

\section{Strengths and limitations}

Furthermore, this review reports factors that (may) influence the severity and outcome of an anastomotic leakage. A potential limitation of this review is that many studies were excluded based on title and abstract due to not reporting treatment results for cervical and intrathoracic leakage separately. Aware of the fact that more data on anastomotic leakage is available, we did not include these studies because it would not contribute in finding an answer to our research question. In addition, the methodological quality of the included studies was limited. Half of the studies reported results of a highly selected group of patients, which makes the external validity of these data weak. All studies were retrospective and included a limited number of patients. The objective of the present study was to investigate the treatment of anastomotic leakages; however, due to a lack of reported baseline characteristics and definitions of anastomotic 
Table 5 Other outcome parameters

\begin{tabular}{|c|c|c|c|}
\hline & Studies, $n$ & Included patients, $n$ & Outcome, $n(\%)$ \\
\hline \multicolumn{4}{|l|}{ Mortality rate } \\
\hline Conservative & 6 & 78 & $9(12 \%)$ \\
\hline \multicolumn{4}{|l|}{ Endoscopic } \\
\hline Stent & 7 & 76 & $11(14 \%)$ \\
\hline Drainage & 4 & 95 & $8(8 \%)$ \\
\hline Endoscopic VAC & 1 & 5 & $0(0 \%)$ \\
\hline Dilatation & 2 & 13 & $0(0 \%)$ \\
\hline Surgical & 1 & 6 & $3(50 \%)$ \\
\hline \multicolumn{4}{|l|}{ Success rate } \\
\hline Conservative & 6 & 78 & 69 (88\%) \\
\hline \multicolumn{4}{|l|}{ Endoscopic } \\
\hline Stent & 7 & 76 & $57(75 \%)$ \\
\hline Drainage & 4 & 95 & 86 (91\%) \\
\hline Endoscopic VAC & 1 & 5 & $5(100 \%)$ \\
\hline Dilatation & 2 & 13 & $13(100 \%)$ \\
\hline Surgical & 1 & 6 & $3(50 \%)$ \\
\hline \multicolumn{4}{|l|}{ Severe complications } \\
\hline Conservative & 4 & 56 & $9(16 \%)$ \\
\hline \multicolumn{4}{|l|}{ Endoscopic } \\
\hline Stent & 6 & 58 & 27 (47\%) \\
\hline Drainage & 3 & 72 & $13(18 \%)$ \\
\hline Endoscopic VAC & & NA & NA \\
\hline Dilatation & 2 & 13 & $5(38 \%)$ \\
\hline Surgical & 1 & 6 & $3(50 \%)$ \\
\hline \multicolumn{4}{|l|}{ Reinterventions } \\
\hline Conservative & 2 & 36 & $5(36 \%)$ \\
\hline \multicolumn{4}{|l|}{ Endoscopic } \\
\hline Stent & 6 & 67 & $27(40 \%)$ \\
\hline Drainage & 2 & 47 & $10(21 \%)$ \\
\hline Endoscopic VAC & NA & NA & NA \\
\hline Dilatation & 2 & 13 & $5(38 \%)$ \\
\hline Surgical & NA & NA & NA \\
\hline \multicolumn{4}{|c|}{ Mean number of reinterventions } \\
\hline Conservative & 2 & 36 & 3 \\
\hline \multicolumn{4}{|l|}{ Endoscopic } \\
\hline Stent & 6 & 67 & 1 \\
\hline Drainage & 2 & 47 & 1 \\
\hline Endoscopic VAC & NA & NA & NA \\
\hline Dilatation & 2 & 13 & 4 \\
\hline Surgical & NA & NA & NA \\
\hline \multicolumn{4}{|l|}{ Reoperations } \\
\hline Conservative & 3 & 53 & $2(4 \%)$ \\
\hline \multicolumn{4}{|l|}{ Endoscopic } \\
\hline Stent & 4 & 46 & $6(13 \%)$ \\
\hline
\end{tabular}

Table 5 Other outcome parameters (Continued)

\begin{tabular}{|c|c|c|c|}
\hline & Studies, $n$ & Included patients, $n$ & Outcome, $n(\%)$ \\
\hline Drainage & 1 & 23 & $1(4 \%)$ \\
\hline Endoscopic VAC & NA & NA & NA \\
\hline Dilatation & NA & NA & NA \\
\hline Surgical & 1 & 6 & $2(33 \%)$ \\
\hline \multicolumn{4}{|l|}{ Hospital length of stay } \\
\hline Conservative & 4 & 65 & 41 days \\
\hline \multicolumn{4}{|l|}{ Endoscopic } \\
\hline Stent & 4 & 51 & 37 days \\
\hline Drainage & 2 & 48 & 42 days \\
\hline Endoscopic VAC & NA & NA & NA \\
\hline Dilatation & NA & NA & NA \\
\hline Surgical & NA & NA & NA \\
\hline \multicolumn{4}{|l|}{ ICU length of stay } \\
\hline Conservative & 2 & 40 & 16 days \\
\hline \multicolumn{4}{|l|}{ Endoscopic } \\
\hline Stent & 1 & 9 & 25 days \\
\hline Drainage & 1 & 23 & 12 days \\
\hline Endoscopic VAC & NA & NA & NA \\
\hline Dilatation & NA & NA & NA \\
\hline Surgical & NA & NA & NA \\
\hline
\end{tabular}

VAC vacuum-assisted closure, NA not available

leakages, it remains unclear whether these cohorts and leakage rates are comparable. Furthermore, additional treatments (e.g., nil by mouth, nutritional support, gastric drainage) which patients received alongside the investigational treatment were different between studies or not specified. Characterization of the leak and definitions of outcome parameters used were frequently lacking and not comparable between studies. Because of the heterogeneity of the included studies, performing a meta-analysis was deemed not scientifically and clinically relevant. Finally, multiple forms of bias were found in the data, i.e., in 13 studies, the follow-up length was not reported or too short to find long-term complications, i.e., stricture and fistula formation, or stent migration and 10 studies reported on selected cases (i.e., excluding the critically ill and intensive care patients).

\section{Clinical implications}

Based on the currently available evidence, it is not possible to provide a uniform strategy for the treatment of anastomotic leakage after esophagectomy. Although achieving the aim of this systematic review was not entirely possible with the currently available evidence, this review is highly instrumental in exposing the limitations of the current evidence and therefore uncovering areas for future research. Firstly, it is important to separately report outcomes of intrathoracic and cervical anastomotic leaks, 
Table 6 Outcomes intrathoracic anastomosis

\begin{tabular}{|c|c|c|c|}
\hline & Studies $(n)$ & Included patients $(n)$ & Outcome \\
\hline \multicolumn{4}{|l|}{ Mortality rate } \\
\hline Conservative & 4 & 42 & $6(14 \%)$ \\
\hline \multicolumn{4}{|l|}{ Endoscopic } \\
\hline Stent & 4 & 52 & $4(8 \%)$ \\
\hline Drainage & 4 & 95 & $8(8 \%)$ \\
\hline Endoscopic VAC & 1 & 5 & $0(0 \%)$ \\
\hline Surgical & 1 & 6 & $3(50 \%)$ \\
\hline \multicolumn{4}{|l|}{ Success rate } \\
\hline Conservative & 4 & 42 & $36(86 \%)$ \\
\hline \multicolumn{4}{|l|}{ Endoscopic } \\
\hline Stent & 4 & 52 & $40(77 \%)$ \\
\hline Drainage & 4 & 95 & $86(91 \%)$ \\
\hline Endoscopic VAC & 1 & 5 & $5(100 \%)$ \\
\hline Surgical & 1 & 6 & $3(50 \%)$ \\
\hline \multicolumn{4}{|l|}{ Severe complications } \\
\hline Conservative & 2 & 20 & $3(15 \%)$ \\
\hline \multicolumn{4}{|l|}{ Endoscopic } \\
\hline Stent & 3 & 34 & $14(41 \%)$ \\
\hline Drainage & 3 & 72 & $13(18 \%)$ \\
\hline Endoscopic VAC & NA & NA & NA \\
\hline Surgical & 1 & 6 & $3(50 \%)$ \\
\hline \multicolumn{4}{|l|}{ Reinterventions } \\
\hline Conservative & NA & NA & NA \\
\hline \multicolumn{4}{|l|}{ Endoscopic } \\
\hline Stent & 4 & 52 & $19(37 \%)$ \\
\hline Drainage & 2 & 47 & $10(21 \%)$ \\
\hline Endoscopic VAC & NA & NA & NA \\
\hline Surgical & NA & NA & NA \\
\hline \multicolumn{4}{|c|}{ Mean number of reinterventions } \\
\hline Conservative & NA & NA & NA \\
\hline \multicolumn{4}{|l|}{ Endoscopic } \\
\hline Stent & 4 & 52 & 1 \\
\hline Drainage & 2 & 47 & 1 \\
\hline Endoscopic VAC & NA & NA & NA \\
\hline Surgical & NA & NA & NA \\
\hline \multicolumn{4}{|l|}{ Reoperations } \\
\hline Conservative & 2 & 30 & $1(33 \%)$ \\
\hline \multicolumn{4}{|l|}{ Endoscopic } \\
\hline Stent & 3 & 37 & $2(5 \%)$ \\
\hline Drainage & 1 & 23 & $1(4 \%)$ \\
\hline Endoscopic VAC & NA & NA & NA \\
\hline Surgical & NA & NA & $2(33 \%)$ \\
\hline \multicolumn{4}{|l|}{ Hospital length of stay } \\
\hline Conservative & 3 & 29 & 64 days \\
\hline
\end{tabular}

Table 6 Outcomes intrathoracic anastomosis (Continued)

\begin{tabular}{llll}
\hline & Studies $(n)$ & Included patients $(n)$ & Outcome \\
\hline Endoscopic & & & \\
Stent & 3 & 42 & 38 days \\
Drainage & 2 & 48 & 42 days \\
Endoscopic VAC & NA & NA & NA \\
Surgical & & & NA \\
ICU length of stay & & & \\
Conservative & 1 & 17 & 34 days \\
Endoscopic & & & 25 days \\
Stent & 1 & 9 & 12 days \\
Drainage & 1 & 23 & NA \\
Endoscopic VAC & NA & NA & NA \\
Surgical & NA & NA
\end{tabular}

NA not available

because evidence suggests that these are separate entities and probably necessitate different treatment strategies [4, 34]. Secondly, a uniform definition of anastomotic leakage, including factors that may influence the severity of anastomotic leakages and outcome parameters, should be described to make data transparent and comparable between studies. These factors may include length of the leak, circumference of the leak, condition of the gastric tube (vital, ischemic, necrotic), and contamination caused by the leak [35]. Adequate description of anastomotic leakage makes it possible to evaluate whether these factors actually contribute to leak severity and compare different treatment strategies. This may lead to an anastomotic leakage severity score. A score based on leakage characteristics, rather than a scoring system based on leakage therapy (e.g., the ECCG grading system [36]), is essential for providing clinicians an optimal treatment strategy for patients with an anastomotic leak. No evidence-based recommendations could be provided from the literature. For the current practice, we recommend, based on our experiences, all patients with an anastomotic leakage should be treated with intravenous antibiotics, nasogastric tube drainage, and where possible enteral feeding through a jejunal feeding tube or jejunostomy. In case of a cervical anastomosis, the neck wound should be opened. Additional interventions depend on the sequelae of the leak and the condition of the patient. Undrained collections of the mediastinum and thoracic cavity should be drained by surgical or radiological placed percutaneous drains and/or an endoscopic suction tube through the anastomotic defect. If drainage is insufficient or in case of more extensive contamination, a more aggressive strategy may be appropriate and drainage can be performed by video-assisted thoracoscopic surgery (VATS) or thoracotomy. In addition to 
Table 7 Outcomes cervical anastomosis

\begin{tabular}{|c|c|c|c|}
\hline & Studies $(n)$ & Included patients $(n)$ & Outcome \\
\hline \multicolumn{4}{|l|}{ Mortality rate } \\
\hline Conservative & 2 & 36 & $3(8 \%)$ \\
\hline \multicolumn{4}{|l|}{ Endoscopic } \\
\hline Stent & 3 & 24 & $7(29 \%)$ \\
\hline Dilatation & 2 & 13 & $0(0 \%)$ \\
\hline \multicolumn{4}{|l|}{ Success rate } \\
\hline Conservative & 2 & 36 & $33(92 \%)$ \\
\hline \multicolumn{4}{|l|}{ Endoscopic } \\
\hline Stent & 3 & 24 & $17(71 \%)$ \\
\hline Dilatation & 2 & 13 & $13(100 \%)$ \\
\hline \multicolumn{4}{|c|}{ Severe complications } \\
\hline Conservative & 2 & 36 & $6(17 \%)$ \\
\hline \multicolumn{4}{|l|}{ Endoscopic } \\
\hline Stent & 3 & 24 & $13(54 \%)$ \\
\hline Dilatation & 2 & 13 & $5(38 \%)$ \\
\hline \multicolumn{4}{|l|}{ Reinterventions } \\
\hline Conservative & 2 & 36 & $5(14 \%)$ \\
\hline \multicolumn{4}{|l|}{ Endoscopic } \\
\hline Stent & 2 & 15 & $8(53 \%)$ \\
\hline Dilatation & 2 & 13 & $5(38 \%)$ \\
\hline \multicolumn{4}{|c|}{ Mean number of reinterventions } \\
\hline Conservative & 2 & 36 & 3 \\
\hline \multicolumn{4}{|l|}{ Endoscopic } \\
\hline Stent & 2 & 15 & 1 \\
\hline Dilatation & 2 & 13 & 4 \\
\hline \multicolumn{4}{|l|}{ Reoperations } \\
\hline Conservative & 1 & 23 & $1(4 \%)$ \\
\hline \multicolumn{4}{|l|}{ Endoscopic } \\
\hline Stent & 1 & 9 & $4(44 \%)$ \\
\hline Dilatation & NA & NA & NA \\
\hline \multicolumn{4}{|c|}{ Hospital length of stay } \\
\hline Conservative & 2 & 36 & 22 days \\
\hline \multicolumn{4}{|l|}{ Endoscopic } \\
\hline Stent & 1 & 9 & 36 days \\
\hline Dilatation & NA & NA & NA \\
\hline \multicolumn{4}{|c|}{ ICU length of stay } \\
\hline Conservative & 1 & 23 & 2 days \\
\hline \multicolumn{4}{|l|}{ Endoscopic } \\
\hline Stent & NA & NA & NA \\
\hline Dilatation & NA & NA & NA \\
\hline
\end{tabular}

drainage of fluid collections, the defect can be closed surgically or covered/closed with an endoscopically placed stent or E-VAC system. However, more data is needed to evaluate the effectiveness of these recommendations. In this review, we showed that there are multiple treatments and strategies to treat anastomotic leakage. Together with the incidence of anastomotic leakage, it is unlikely that single-center cohort studies will include enough patients to provide robust data for an anastomotic leakage treatment strategy. More detailed data from a larger cohort is urgently needed to provide an evidence-based treatment strategy for anastomotic leakage after esophagectomy. Currently, the TENTACLE study (TreatmENT of AnastomotiC Leakage after Esophagectomy), an international retrospective cohort study on patients with an anastomotic leakage after esophagectomy for esophageal cancer, is being performed (NCT03829098) [37]. This study includes standardized characteristics of an anastomotic leakage and has a standardized outcome. This study could provide answers to current issues as which factors determine the severity of the leakage and which treatment options have the best outcomes.

\section{Conclusions}

Due to small cohorts in the included studies, heterogeneity between studies and lack of data regarding leakage characteristics, no evidence supporting a specific treatment for anastomotic leakage after esophagectomy was found. A severity score based on leakage characteristics instead of treatment given is needed for determining the optimal treatment of anastomotic leakage. In the absence of robust evidence-based treatment guidelines, we recommend an individualized treatment depending on sequelae of the leak and condition of the patient.

\section{Additional file}

Additional file 1: Appendix 1. PRISMA 2009 checklist. Appendix 2. The electronic sea. (DOCX $108 \mathrm{~kb}$ )

\section{Abbreviations}

CT: Computer tomography; ICU: Intensive care unit; MIE: Minimally invasive esophagectomy; NA: Not available; PRISMA: Preferred Reporting Items for Systematic Reviews and Meta-analyses; SEMS: Self-expandable metallic stent; VAC: Vacuum-assisted closure

Acknowledgements

Not applicable.

Funding

None of the authors received funding to perform this research.

Availability of data and materials

The datasets used and/or analyzed during the current study are available from the corresponding author on reasonable request.

Authors' contributions

$\mathrm{CR}, \mathrm{MV}$, and $\mathrm{SB}$ made substantial contributions to the conception and design of this study. MV and SB collected, analyzed, and interpreted the data of the included studies. CR, FvW, RtB, PS, and MR were major contributors in 
interpreting the data and writing the manuscript. All authors read and approved the final manuscript.

\section{Ethics approval and consent to participate}

Not applicable.

\section{Consent for publication}

Not applicable.

\section{Competing interests}

The authors declare that they have no competing interests.

\section{Publisher's Note}

Springer Nature remains neutral with regard to jurisdictional claims in published maps and institutional affiliations.

\section{Author details}

'Department of Surgery, Radboudumc, Geert Grooteplein Zuid 10, 6525 GA Nijmegen, The Netherlands. ${ }^{2}$ Gastroenterology and Hepatology, Radboudumc, Geert Grooteplein Zuid 10, 6525 GA Nijmegen, The Netherlands. ${ }^{3}$ Operating Rooms and Health Evidence, Radboudumc, Geert Grooteplein Zuid 10, 6525 GA Nijmegen, The Netherlands.

Received: 10 January 2019 Accepted: 14 March 2019

Published online: 04 April 2019

\section{References}

1. Dikken JL, Lemmens VE, Wouters MW, Wijnhoven BP, Siersema PD, Nieuwenhuijzen GA, van Sandick JW, Cats A, Verheij M, Coebergh JW, van de Velde CJ. Increased incidence and survival for oesophageal cancer but not for gastric cardia cancer in the Netherlands. Eur J Cancer. 2012;48(11): 1624-32.

2. Pennathur A, Gibson MK, Jobe BA, Luketich JD. Oesophageal carcinoma. Lancet. 2013;381(9864):400-12.

3. Analysis of DUCA (Dutch Upper GI Cancer Audit) registration database 2012. http://dica.nl/jaarrapportage-2017/duca.

4. Biere SS, Maas KW, Cuesta MA, van der Peet DL. Cervical or thoracic anastomosis after esophagectomy for cancer: a systematic review and meta-analysis. Dig Surg. 2011;28(1):29-35.

5. Alanezi K, Urschel JD. Mortality secondary to esophageal anastomotic leak. Ann Thorac Cardiovasc Surg. 2004;10(2):71-5.

6. Luketich JD, Pennathur A, Awais O, Levy RM, Keeley S, Shende M, Christie NA, Weksler B, Landreneau RJ, Abbas G, Schuchert MJ, Nason KS. Outcomes after minimally invasive esophagectomy: review of over 1000 patients. Ann Surg. 2012;256(1):95-103.

7. van Heijl M, Gooszen JA, Fockens P, Busch OR, van Lanschot JJ, van Berge Henegouwen MI. Risk factors for development of benign cervical strictures after esophagectomy. Ann Surg. 2010;251(6):1064-9.

8. Blackmon SH, Correa AM, Wynn B, Hofstetter WL, Martin LW, Mehran R, Rice DC, Swiser SG, Walsh GL, Roth JA, Vaporiyan AA. Propensity-matched analysis of three techniques for intrathoracic esophagogastric anastomosis. Ann Thorac Surg. 2007;83(5):1805-13 discussion 13.

9. Martin LW, Hofstetter W, Swisher SG, Roth JA. Management of intrathoracic leaks following esophagectomy. Adv Surg. 2006;40:173-90.

10. Schaheen L, Blackmon SH, Nason KS. Optimal approach to the management of intrathoracic esophageal leak following esophagectomy: a systematic review. Am J Surg. 2014:208(4):536-43.

11. PROSPERO. 2015. http://www.crd.york.ac.uk/PROSPERO/display_record. asp?ID=CRD42016032374.

12. Moher D, Liberati A, Tetzlaff J, Altman DG, Group P. Preferred reporting items for systematic reviews and meta-analyses: the PRISMA statement. J Clin Epidemiol. 2009:62(10):1006-12

13. Wells G SB, Shea B, O'Connell D, Peterson J, Welch V, Losos M, Tugwell P. The Newcastle-Ottawa Scale (NOS) for assessing the quality of nonrandomized studies in meta-analyses. http://www.ohri.ca/programs/ clinical epidemiology/oxford.asp.

14. Dindo D, Demartines N, Clavien PA. Classification of surgical complications: a new proposal with evaluation in a cohort of 6336 patients and results of a survey. Ann Surg. 2004;240(2):205-13.
15. Al-issa MA, Petersen TI, Taha AY, Shehatha JS. The role of esophageal stent placement in the management of postesophagectomy anastomotic leak. Saudi J Gastroenterol. 2014;20(1):39-42.

16. Bhasin DK, Sharma BC, Gupta NM, Sinha SK, Singh K. Endoscopic dilation for treatment of anastomotic leaks following transhiatal esophagectomy. Endoscopy. 2000:32(6):469-71.

17. Bludau M, Holscher AH, Herbold T, Leers JM, Gutschow C, Fuchs H, Schröder W. Management of upper intestinal leaks using an endoscopic vacuum-assisted closure system (E-VAC). Surg Endosc. 2014;28(3):896-901.

18. Griffin SM, Lamb PJ, Dresner SM, Richardson DL, Hayes N. Diagnosis and management of a mediastinal leak following radical oesophagectomy. Brit J Surg. 2001;88(10):1346-51.

19. Holscher AH, Schroder W, Bollschweiler E, Beckurts KT, Schneider PM. How safe is high intrathoracic esophagogastrostomy? Chirurg. 2003;74(8):726-33.

20. Hu Z, Yin R, Fan X, Zhang Q, Feng C, Yuan F, Chen J, Jiang F, Li N, Xu $\mathrm{L}$. Treatment of intrathoracic anastomotic leak by nose fistula tube drainage after esophagectomy for cancer. Dis Esophagus. 2011;24(2): $100-7$.

21. Hunerbein M, Stroszczynski C, Moesta KT, Schlag PM. Treatment of thoracic anastomotic leaks after esophagectomy with self-expanding plastic stents. Ann Surg. 2004;240(5):801-7.

22. Jiang F, Yu MF, Ren BH, Yin GW, Zhang $Q$, Xu L. Nasogastric placement of sump tube through the leak for the treatment of esophagogastric anastomotic leak after esophagectomy for esophageal carcinoma. J Surg Res. 2011;171(2):448-51.

23. Kauer WK, Stein HJ, Dittler HJ, Siewert JR. Stent implantation as a treatment option in patients with thoracic anastomotic leaks after esophagectomy. Surg Endosc. 2008;22(1):50-3.

24. Korst RJ, Port JL, Lee PC, Altorki NK. Intrathoracic manifestations of cervical anastomotic leaks after transthoracic esophagectomy for carcinoma. Ann Thorac Surg. 2005:80(4):1185-90.

25. Larburu Etxaniz S, Gonzales Reyna J, Elorza Orue JL, Asensio Gallego I, Diez del Val I, Eizaguirre Letamendia E, Mar Medina B. Cervical anastomotic leak after esophagectomy: diagnosis and management. Cir Esp. 2013;91(1):31-7.

26. Leenders BJ, Stronkhorst A, Smulders FJ, Nieuwenhuijzen GA, Gilissen LP. Removable and repositionable covered metal self-expandable stents for leaks after upper gastrointestinal surgery: experiences in a tertiary referral hospital. Surg Endosc. 2013;27(8):2751-9.

27. Lindenmann J, Matzi V, Porubsky C, Anegg U, Sankin O, Gabor S, Neuboeck N, Maier A, Smolle-Juettner FM. Self-expandable covered metal tracheal type stent for sealing cervical anastomotic leak after esophagectomy and gastric pull-up: pitfalls and possibilities. Ann Thorac Surg. 2008;85(1):354-6.

28. Orringer MB, Lemmer $\mathrm{JH}$. Early dilation in the treatment of esophageal disruption. Ann Thorac Surg. 1986;42(5):536-9.

29. Qin J, Li Y, Zhang R, Yan M, Wang G, Liu B. Treatment of esophagogastric anastomotic leak with perianastomotic drain. J Thorac Oncol. 2010;5(2):251-3.

30. Shuto K, Kono T, Akutsu Y, Uesato M, Mori M, Matsuo K, Kosugi C, Hirano A, Tanaka K, Okazumi S, Koda K, Matsubara H. Naso-esophageal extraluminal drainage for postoperative anastomotic leak after thoracic esophagectomy for patients with esophageal cancer. Dis Esophagus. 2017:30(3):1-9.

31. Tuebergen D, Rijcken E, Mennigen R, Hopkins AM, Senninger $N$, Bruewer M. Treatment of thoracic esophageal anastomotic leaks and esophageal perforations with endoluminal stents: efficacy and current limitations. J Gastrointest Surg. 2008;12(7):1168-76.

32. van Rossum PS, Haverkamp L, Carvello M, Ruurda JP, van Hillegersberg R. Management and outcome of cervical versus intrathoracic manifestation of cervical anastomotic leakage after transthoracic esophagectomy for cancer. Dis Esophagus. 2017;30(1):1-8.

33. Yin G, Xu Q, Chen S, Bai X, Jiang F, Zhang Q, Xu L, Xu W. Fluoroscopically guided three-tube insertion for the treatment of postoperative gastroesophageal anastomotic leakage. Korean J Radiol. 2012;13(2):182-8.

34. Gooszen JAH, Goense L, Gisbertz SS, Ruurda JP, van Hillegersberg R, van Berge Henegouwen MI. Intrathoracic versus cervical anastomosis and predictors of anastomotic leakage after oesophagectomy for cancer. $\mathrm{Br} J$ Surg. 2018;105(5):552-60. 
35. Messager M, Warlaumont M, Renaud F, Marin H, Branche J, Piessen G, Mariette C. Recent improvements in the management of esophageal anastomotic leak after surgery for cancer. Eur J Surg Oncol. 2017;43(2):258-69.

36. Low DE, Alderson D, Cecconello I, Chang AC, Darling GE, D'Journo XB,

Griffin SM, Hölscher AH, Hofstetter WL, Jobe BA, Kitagawa Y, Kucharczuk JC, Law SY, Lerut TE, Maynard N, Pera M, Peters JH, Pramesh CS, Reynolds JV,

Smithers BM, van Lanschot JJ. International consensus on standardization of data collection for complications associated with esophagectomy:

Esophagectomy Complications Consensus Group (ECCG). Ann Surg. 2015; 262(2):286-9.

37. TreatmENT of AnastomotiC Leakage After Esophagectomy (TENTACLE

study) (NCT03829098). 2019. https://clinicaltrials.gov/ct2/show/NCT03829098

Ready to submit your research? Choose BMC and benefit from:

- fast, convenient online submission

- thorough peer review by experienced researchers in your field

- rapid publication on acceptance

- support for research data, including large and complex data types

- gold Open Access which fosters wider collaboration and increased citations

- maximum visibility for your research: over $100 \mathrm{M}$ website views per year

At BMC, research is always in progress.

Learn more biomedcentral.com/submissions 